\title{
Fundamental Limits on NOx Reduction by Plasma
}

\author{
B. M. Penetrante \\ M. C. Hsiao, B. T. Merritt, G. E. Vogtlin \\ This paper was prepared for submittal to the \\ 1997 SAE International Spring Fuels \& Lubricants Meeting \& Exposition \\ Dearborn, Michigan \\ May 5-8, 1997
}

April 7, 1997

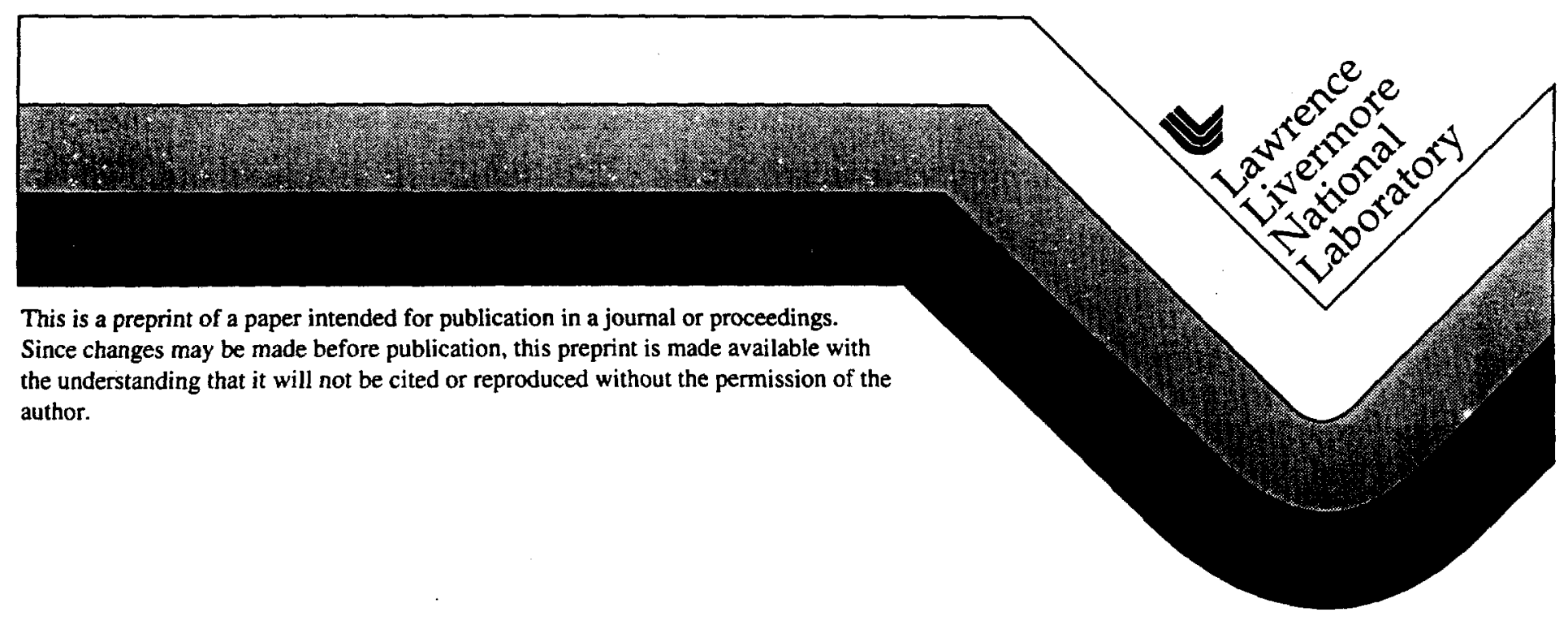




\section{DISCLAIMER}

This document was prepared as an account of work sponsored by an agency of the United States Government. Neither the United States Government nor the University of California nor any of their employees, makes any warranty, express or implied, or assumes any legal liability or responsibility for the accuracy, completeness, or usefulness of any information, apparatus, product, or process

disclosed, or represents that its use would not infringe privately owned rights. Reference herein to any specific commercial product, process, or service by trade name, trademark, manufacturer, or otherwise, does not necessarily constitute or imply its endorsement, recommendation, or favoring by the United States Government or the University of California. The views and opinions of authors expressed herein do not necessarily state or reflect those of the United States Government or the University of California, and shall not be used for advertising or product endorsement purposes. 


\title{
Fundamental Limits on $\mathrm{NO}_{\mathrm{x}}$ Reduction by Plasma
}

\author{
B. M. Penetrante, M. C. Hsiao, B. T. Merritt and G. E. Vogtlin \\ Lawrence Livermore National Laboratory
}

\section{ABSTRACT}

This paper discusses the gas-phase reaction mechanisms for removal of $\mathrm{NO}_{\mathbf{x}}$ in a plasma. The effect of oxygen content on the competition between the reduction and oxidation processes is discussed. The effect of the electron kinetic energy distribution on the radical production and subsequent chemistry is then discussed in order to predict the best performance that can be achieved for $\mathrm{NO}_{\mathrm{x}}$ reduction using the plasma abne. The fundamental limit on the minimum electrical energy consumption that will be required to implement $N O_{x}$ reduction in any type of plasma reactor is established.

\section{INTRODUCTION}

Plasma-based methods for the abatement of $\mathrm{NO}_{x}$ in gas streams are being investigated in a number of laboratories [Ref. 1]. One critical issue in the use of plasmas is the electrical energy consumption. For applications to trucks and cars, another critical issue is whether the plasma is removing $\mathrm{NO}_{x}$ by chemical reduction to benign gases.

Plasma processing requires electrical energy. There are many ideas being proposed in an attempt to minimize the electrical energy consumption, including (a) optimization of the electrode structure of the plasma reactor, (b) optimization of the voltage waveform applied to the plasma reactor, and (c) taking advantage of heterogeneous reactions.

thas been difficult to assess and compare the performance of various kinds of plasma reactors. The data presented in the literature using different kinds of reactors often were measured under different gas conditions. In many cases, the data are presented in a way that makes $t$ impossible for the reader to determine the energy consumption of the reactor.

There is also some controversy on what type of efficiency should be improved. There are two kinds of efficiencies that concern the plasma processing community: (a) electrical conversion efficiency, and (b) chemical processing efficiency. The electrical conversion efficiency refers to the efficiency for converting wall plug electrical power into power deposited by the electrons into the plasma. The chemical processing efficiency refers to the amount of pollutant removed or decomposed for a given amount of energy deposited into the plasma. The latter is often expressed in terms of the specific energy consumption in units such as electron volts $(\mathrm{eV})$ per molecule of $\mathrm{NO}_{\mathrm{x}}$, or grams of $\mathrm{NO}_{\mathrm{x}}$ per kW-hr. Obviously, if the fundamental limit on the chemical processing efficiency cannot satisfy user requirements, then the development of a $100 \%$ electrically efficient reactor will never satisfy those requirements.

Much work has been done in the application of non-thermal plasma methods to the treatment of flue gases from power plants [Ref. 2]. I should be noted, however, that in power plant flue gas treatment applications, the purpose of the plasma is to oxidize NO to $\mathrm{NO}_{2}$, and eventually to nitric acid. The desired products, in the form of ammonium salts, are then obtained by mixing ammonia with the formed acids. Some form of scrubbing is required to collect the final products.

For applications to the treatment of exhausts from cars and trucks, it is very important to make a distinction between NO removal by chemical oxidation and NO removal by chemical reduction. To avoid the need for scrubbing of process products, the desired method of NO removal is by chemical reduction; i.e. the conversion of $\mathrm{NO}$ to benign gaseous products like $\mathrm{N}_{2}$ and $\mathrm{O}_{2}$. In the plasma processing literature, many authors carelessly use the term "NO reduction" even when the "NO removal" is accomplished by oxidation to $\mathrm{NO}_{2}$ and nitric acid.

Heterogeneous reactions in the plasma reactor can also take place in oxidative and reductive modes. Enhanced absorption of $\mathrm{NO}_{2}$ and nitric acid to 
particulates and reactor walls can often be mistaken for chemical reduction. In power plant flue gas treatment applications, there is an abundance of aerosol particles resulting from the plasma oxidation. These aerosols can either enhance the scrubbing of other oxidation products or promote the oxidation process itself. It is very important to establish if the heterogeneous reactions are oxidative or reductive. This can be accomplished through diligent control of operating conditions and careful analysis of process products. However, such basic experiments are best done first under wellcontrolled simulated conditions rather than actual engine exhaust conditions.

This paper deals with the gaseous phase reactions in the plasma. The main objective is to establish the fundamental limit on the minimum electrical energy consumption that will be required to implement $\mathrm{NO}_{\mathrm{x}}$ reduction by the plasma alone. The effect of background gas composition, particularly the oxygen content, on the competition between the reduction and oxidation processes will be discussed.

\section{DISSOCIATION ENERGY LIMIT}

The intent in using a non-thermal plasma is to selectively transfer the input electrical energy to the electrons. An ideal situation would be where the kinetic energy of the electrons is dissipated entirely in the dissociation of NO molecules. The energy required to dissociate an NO molecule is $6.5 \mathrm{eV}$. This corresponds to the dissociation of $40 \mathrm{ppm}$ of NO per Joule/liter of input energy density, as shown in Figure 1. The input energy density is the power deposited into the gas divided by the gas flow rate. For example, assuming a $100 \mathrm{~kW}$ engine puts out $500 \mathrm{ppm}$ of NO an exhaust flow rate of 1.5 liters per second per $k W$, then the minimum power needed by the plasma to dissociate all the NO would be about $2 \mathrm{~kW}$.

Because of the relatively low concentration of NO in the exhaust gas, direct dissociation of NO by the electrons is not probable. The kinetic energy of the electrons is deposited primarily into the major exhaust gas components, $\mathrm{N}_{2}$ and $\mathrm{O}_{2}$. The electrons could lose considerable energy through reactions, such as the vibrational excitation of $\mathrm{N}_{2}$, which do not promote the dissociation of NO.

\section{RADICAL PRODUCTION LIMIT}

The most useful deposition of electron kinetic energy into $\mathrm{N}_{2}$ and $\mathrm{O}_{2}$ is associated with the production of $\mathrm{N}$ and $\mathrm{O}$ radicals through electron-impact dissociation:

$$
\begin{aligned}
& e+N_{2} \rightarrow e+N\left({ }^{4} S\right)+N\left({ }^{4} S\right) \\
& e+N_{2} \rightarrow e+N\left({ }^{4} S\right)+N\left({ }^{2} D\right)
\end{aligned}
$$

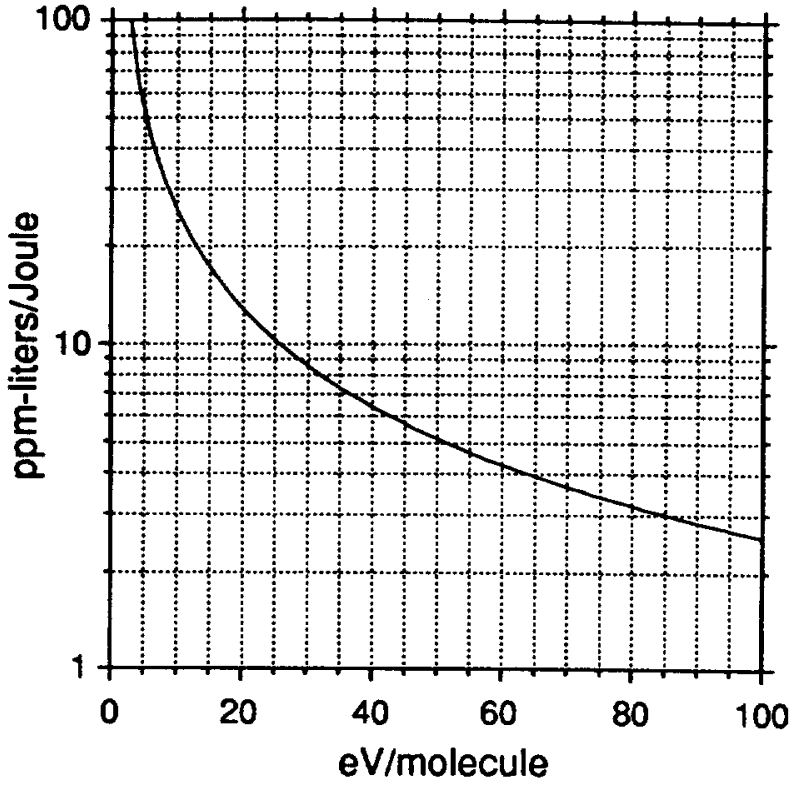

Figure 1. Conversion from "eV per molecule" to "ppmliters per Joule".

$$
\begin{aligned}
& e+\mathrm{O}_{2} \rightarrow e+O\left({ }^{3} P\right)+O\left({ }^{3} P\right) \\
& \left.e+\mathrm{O}_{2} \rightarrow e+O\left({ }^{3} P\right)+O^{1} D\right)
\end{aligned}
$$

where $N\left({ }^{4} S\right)$ and $N\left({ }^{2} D\right)$ are ground-state and metastable excited-state nitrogen atoms, respectively, and $O\left({ }^{3} P\right)$ and $O\left({ }^{1} D\right)$ are ground-state and metastable excited-state oxygen atoms, respectively.

For now let us suppose that the plasma is not producing oxidative radicals. Let us further assume that al nitrogen atoms (labeled simply as $N$ ) can be used entirely for the reduction of NO:

$$
\mathrm{N}+\mathrm{NO} \rightarrow \mathrm{N}_{2}+\mathrm{O}
$$

In this case the energy required to reduce NO is simply determined by the energy required to produce $\mathrm{N}$ from the electron-impact dissociation of $\mathrm{N}_{2}$. What is the energy required to implement this reduction scheme?

Figure 2 shows the G-value for electron-impact dissociation of $\mathrm{N}_{2}$. The $\mathrm{G}$-value is defined as the number of reactions per $100 \mathrm{eV}$ of input electrical energy. The $\mathrm{G}$ value depends on the average kinetic energy (mean energy) of the electrons in the plasma. In turn, the electron mean energy depends on the electric field that can be imposed on the plasma. Higher electric fields will accelerate the electrons to higher kinetic energies.

The highest electric field that can be applied while still maintaining a non-thermal plasma is known as the electrical breakdown threshold. Under atmospheric- 
pressure conditions, the electrical breakdown threshold in an $\mathrm{N}_{2}$ or ar discharge plasma corresponds to an electron mean energy of around $4 \mathrm{eV}$. This corresponds to the consumption of $240 \mathrm{eV}$ of electrical energy per $\mathrm{N}$ atom produced. The reader is referred to Ref. [3] for experimental verification of these statements.

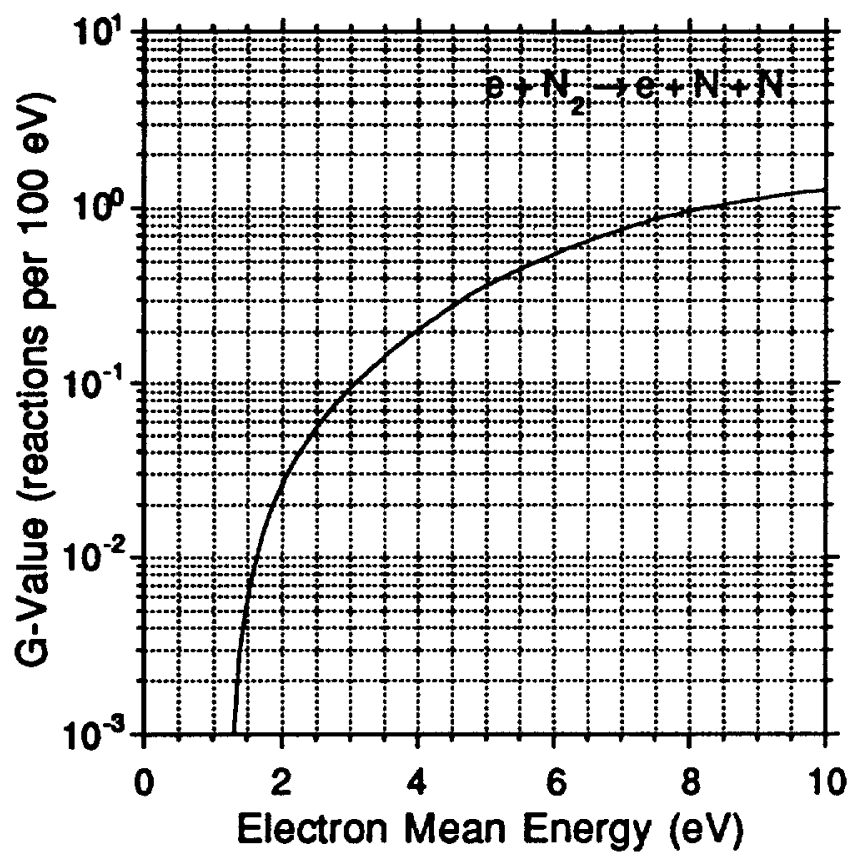

Figure 2. G-value for electron-impact dissociation of $\mathrm{N}_{2}$ as a function of the average kinetic energy of the electrons in the plasma. The G-value is defined as the number of reactions per $100 \mathrm{eV}$ of input electrical energy.

There are several proposals on how the electrical breakdown limit can be increased. For the sake of establishing a fundamental limit, let us assume that a very high electrical breakdown threshold can be achieved in practice. For a very high electron mean energy ( $>10 \mathrm{eV}$ ), the G-value is around $1.25 \mathrm{~N}_{2}$ dissociation reactions per $100 \mathrm{eV}$ of input electrical energy. This corresponds to the consumption of $\mathbf{4 0 \mathrm { eV }}$ of electrical energy per $\mathrm{N}$ atom produced. This is the minimum energy required to produce an $\mathbf{N}$ atom even under the most ideal plasma condition. This condition can be achieved when very high kinetic energy electrons are injected into the gas stream, as verified experimentally in Ref. [4]. Based on reaction (3), the electrical energy required to reduce an NO molecule is $40 \mathrm{eV}$. This corresponds to the reduction of $6.5 \mathrm{ppm}$ of NO per Joule/iter of input electrical energy density. Using the same example assuming a $100 \mathrm{~kW}$ engine putting out $500 \mathrm{ppm}$ of $\mathrm{NO}$ at an exhaust flow rate of 1.5 liters per second per $\mathrm{kW}$, the minimum power needed by the plasma to reduce al the NO would be greater than $10 \mathrm{~kW}$.

\section{EFFECT OF OXYGEN}

There are several problems associated with the presence of $\mathrm{O}_{2}$. These are:

(a) The dissociation energy of $\mathrm{O}_{2}$ is smaller than that of $\mathrm{N}_{2}$. The dissociation of $\mathrm{O}_{2}$ will produce only oxidative radicals. With $\mathrm{O}_{2}$ concentrations of $5 \%$ or more, a significant fraction of the input electrical power is dissipated in the dissociation of $\mathrm{O}_{2}$. The ground state oxygen atoms, $\mathrm{O}\left({ }^{3} \mathrm{P}\right)$, convert $\mathrm{NO}$ to $\mathrm{NO}_{2}$ :

$$
\mathrm{O}(3 \mathrm{P})+\mathrm{NO}+\mathrm{M} \rightarrow \mathrm{NO}_{2}+\mathrm{M}
$$

(b) The creation of metastable atomic nitrogen, particulary $N\left({ }^{2} D\right)$, can enhance undesired reactions in the presence of $\mathrm{O}_{2}$. Rather than reducing $\mathrm{NO}$, the $\mathrm{N}\left({ }^{2} \mathrm{D}\right)$ species would react with $\mathrm{O}_{2}$ to produce $\mathrm{NO}$ :

$$
\mathrm{N}\left({ }^{2} \mathrm{D}\right)+\mathrm{O}_{2} \rightarrow \mathrm{NO}+\mathrm{O}
$$

(c) The metastable atomic oxygen, $O\left({ }^{1} D\right)$, reacts with $\mathrm{H}_{2} \mathrm{O}$ to produce $\mathrm{OH}$ radicals. The $\mathrm{OH}$ radicals convert $\mathrm{NO}$ and $\mathrm{NO}_{2}$ to nitrous acid and nitric acid, respectively.

Figure 3 shows the $N$ and $O$ radical production efficiencies (number of radicals produced per $100 \mathrm{eV}$ of electrical energy input) as functions of the average kinetic energy of the electrons in a plasma for a gas mixture consisting of $10 \% \mathrm{O}_{2}, 10 \% \mathrm{CO}_{2}, 5 \% \mathrm{H}_{2} \mathrm{O}$ and balance $\mathrm{N}_{2}$.

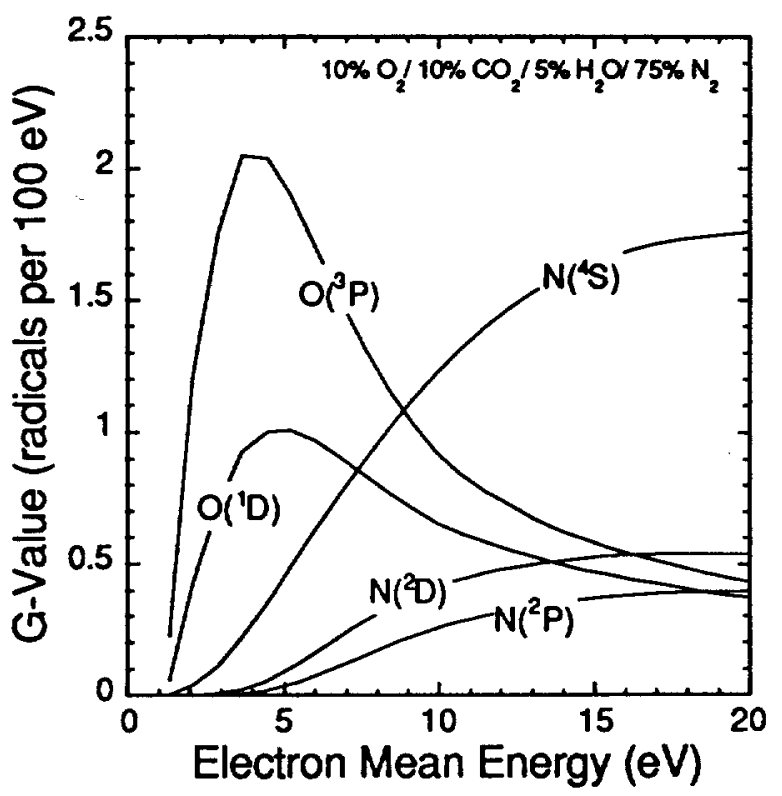

Figure 3. G-values for $\mathrm{N}$ and $\mathrm{O}$ radical production as a function of the average kinetic energy of the electrons in the plasma for a gas mixture consisting of $10 \% \mathrm{O}_{2}, 10 \%$ $\mathrm{CO}_{2}, 5 \% \mathrm{H}_{2} \mathrm{O}$ and balance $\mathrm{N}_{2}$. The $\mathrm{G}$-value here is defined as the number of radicals produced per $100 \mathrm{eV}$ of input electrical energy. 
Because of the electrical breakdown limit, most non-thermal plasma reactors operate in a regime where the average kinetic energy of the electrons is in the $3-6$ $\mathrm{eV}$ range. This is why non-thermal plasma reactors are very good at producing ozone. Unfortunately, the conditions for producing ozone are not the same conditions optimum for reducing $\mathrm{NO}_{\mathbf{x}}$.

High electron mean energies are required to optimize the production of $N\left({ }^{4} S\right)$, which is the only plasma species that can chemically reduce NO. However, at high electron mean energies, a large number of excited nitrogen atoms, $N\left({ }^{2} D\right)$ and $N\left({ }^{2} P\right)$, is produced during electron-impact dissociation of $\mathrm{N}_{2}$. The excited nitrogen atom, $N\left({ }^{2} P\right)$, is rapidly converted to the metastable nitrogen atom $N\left({ }^{2} \mathrm{D}\right)$. Because of the large rate constant for reaction (5) and the large concentration of $\mathrm{O}_{2}$ relative to $\mathrm{NO}$, the $N\left({ }^{2} \mathrm{D}\right)$ species preferentially reacts with $\mathrm{O}_{2}$ to produce NO. A large fraction of the $N\left({ }^{4} S\right)$ is consumed in reducing the NO that is produced by $N\left({ }^{2} D\right)$. This means that even under conditions where the electron kinetic energy is optimum for the dissociation of $\mathrm{N}_{2}$, the presence of $\mathrm{O}_{2}$ will make the minimum electrical energy for NO reduction greater than $40 \mathrm{eV}$ per NO molecule. This corresponds to the reduction of less than $6.5 \mathrm{ppm}$ of NO per Joule/iter of input electrical energy density.

\section{CONCLUSION}

In the absence of heterogeneous reactions, the reduction of NO in a plasma occurs by reaction with atomic nitrogen. Very high electron kinetic energies are required to optimize the production of atomic nitrogen from electron-impact dissociation of $\mathrm{N}_{2}$. When the electron kinetic energy is optimum for $\mathrm{N}_{2}$ dissociation, a large fraction of the atomic nitrogen produced is in the excited state. In the presence of $\mathrm{O}_{2}$, the electrical energy requirement increases because of NO production by the excited atomic nitrogen species. Furthermore, the dissociation of $\mathrm{O}_{2}$ promotes the oxidation of $\mathrm{NO}$ to $\mathrm{NO}_{2}$ and nitric acid. Under the best plasma conditions, the minimum electricity requirement for true chemical reduction corresponds to the reduction of around $6.5 \mathrm{ppm}$ of NO per Joule/liter of input electrical energy density.

\section{ACKNOWLEDGMENT}

The work was performed at Lawrence Livermore National Laboratory under the auspices of the U.S. Department of Energy under Contract Number W-7405ENG-48, with support from the Chemical Sciences Division of the Office of Energy Research and a Cooperative Research and Development Agreement with Cummins Engine Company.

\section{REFERENCES}

[1] Proceedings of the 1995 Diesel Engine Emissions Research Workshop, San Diego, CA, July 2427, 1995, Sect. V, pp. 33-67. (Available from the Office of Transportation Technologies, EE-32, US Department of Energy, 1000 Independence Avenue, SW, Washington, DC 20585. Tel. 202-586-2480).

[2] Non-Thermal Plasma Techniques for Pollution Control: Part B - Electron Beam and Electrical Discharge Processing, edited by B.M. Penetrante and S.E. Schuttheis (Springer-Verlag, Berlin Heidelberg New York, 1993).

[3] B.M. Penetrante, M.C. Hsiao, B.T. Merritt, G.E. Vogtlin, P.H. Wallman, M.Neiger, O. Wolf, T. Hammer and S. Broer, "Pulsed Corona and DielectricBarrier Discharge Processing of $\mathrm{NO}$ in $\mathrm{N}_{2}$ ", Applied Physics Letters 68, 3719-3721 (1996).

[4] B.M. Penetrante, M.C. Hsiao, B.T. Merritt, G.E. Vogtlin, P.H. Wallman, A. Kuthi, C.P. Burkhart and J.R. Bayless, "Electron-Impact Dissociation of Molecular Nitrogen in Atmospheric-Pressure Non-Thermal Plasma Reactors", Applied Physics Letters 67, 3096-3098 (1995). 


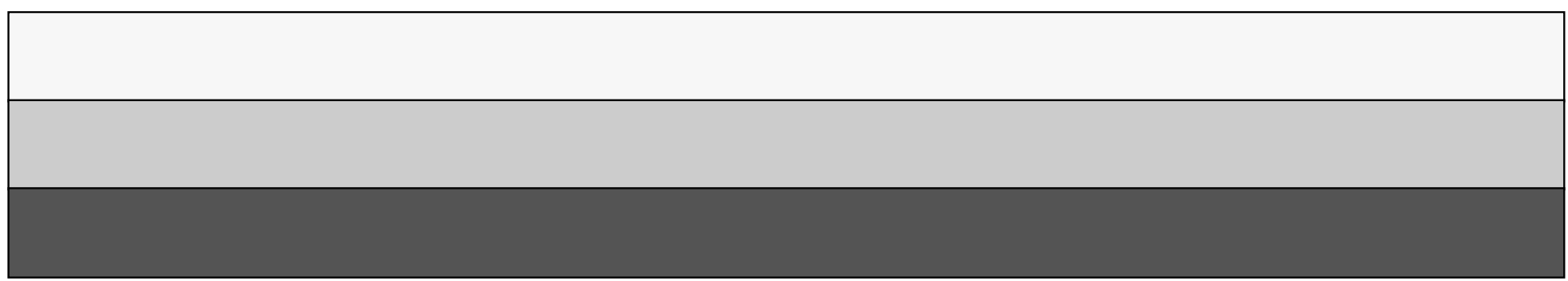

